\title{
Practical Application of NASA-Langley Advanced Satellite Products to In-flight Icing Nowcasts
}

\author{
Ben C. Bernstein ${ }^{1}$ and Cory A. Wolff. ${ }^{2}$ \\ National Center for Atmospheric Research, Boulder CO 80301 \\ and \\ Patrick Minnis ${ }^{3}$ \\ NASA Langley Research Center, Hampton VA 23681
}

\begin{abstract}
Experimental satellite-based icing products developed by the NASA Langley Research Center provide new tools to identify the locations of icing and its intensity. Since 1997, research forecasters at the National Center for Atmospheric Research (NCAR) have been helping to guide the NASA Glenn Research Center's Twin Otter aircraft into and out of clouds and precipitation for the purpose of characterizing in-flight icing conditions, including supercooled large drops, the accretions that result from such encounters and their effect on aircraft performance. Since the winter of 2003-04, the NASA Langley satellite products have been evaluated as part of this process, and are being considered as an input to NCAR's automated Current Icing Potential (CIP) products. This has already been accomplished for a relatively straightforward icing event, but many icing events have much more complex characteristics, providing additional challenges to all icing diagnosis tools. In this paper, four icing events with a variety of characteristics will be examined, with a focus on the NASA Langley satellite retrievals that were available in real time and their implications for icing nowcasting and potential applications in CIP.
\end{abstract}

\section{Nomenclature}

$C I P=$ Current Icing Potential

$F A A=$ Federal Aviation Administration

$F S S P=$ Forward Scattering Spectrometer Probe

$G D C P=$ GOES Derived Cloud Product

GOES = Geostationary Operational Environmental Satellite

$K C L E=$ Cleveland, Ohio

$K Y N G=$ Youngstown, Ohio

$L W C=$ Liquid Water Content

$L W P=$ Liquid Water Path

$M V D=$ Median Volumetric Diameter

NASA $=$ National Aeronautics and Space Administration

$N C A R=$ National Center for Atmospheric Research

NEXRAD = NEXt generation RADar

$O A P=$ Optical Array Probe

REFF = Effective Drop Radius

$S L D=$ Supercooled Large Drops

$S L W=$ Supercooled Liquid Water

$S L W C=$ Supercooled Liquid Water Content

T11= Brightness Temperature at $11 \mu \mathrm{m}$

\footnotetext{
${ }^{1}$ Associate Scientist, Res. Applications Laboratory, National Center for Atmospheric Research, AIAA Member.

${ }^{2}$ Associate Scientist, Res. Applications Laboratory, National Center for Atmospheric Research.

${ }^{3}$ Senior Research Scientist, Climate Science Branch, Science Directorate, NASA Langley Research Center.
} 


\section{Introduction}

$\mathrm{T}$

HERE is a great deal of variety to in-flight icing events. They occur on scales that vary from tens of meters to hundreds of kilometers and are driven by meteorological features that include inner-cloud turbulent motions, cloud edges, variability in cloud layer depth and cloud top temperature, frontal zones and interaction with terrain and water surfaces below. In-situ observations of icing clouds have indicated large fluctuations in supercooled liquid water content (LWC) during some icing encounters (as in Fig. 1). Even those measurements taken within what appeared to be rather consistent and widespread clouds still had significant variability embedded within them.

Experience from short-term forecasting for in-flight icing flight programs has shown that satellite imagery provides great value when determining many aspects of sub-freezing clouds, including clues about microphysical composition and the homogeneity thereof. Recently, the NASA Langley Research Center developed a suite of realtime GOES Derived Cloud Products (GDCPs) that provide assessments of these parameters, including cloud phase (PHASE), liquid water path (LWP) and drop effective radius (REFF) $)^{1,2}$. LWP represents a vertically integrated liquid water value for the column. NCAR forecasters have found that for a typical, single-layer, liquid water, smalldrop dominated cloud, the cloud top LWC can be roughly approximated by dividing LWP by a factor of 1000-2000 (e.g. an LWP of $200 \mathrm{gm}^{-2}$ roughly translates to a cloud top LWC of 0.1-0.2 $\mathrm{gm}^{-3}$ ). When cloud tops are comprised of only water, REFF provides an estimate of the drop radii.

The GDCPs have shown to be of considerable value for the diagnosis of icing and are being considered for integration into the FAA's operational Current Icing Potential algorithm (CIP) ${ }^{3}$, including its new icing severity product ${ }^{4,5}$. One key element of CIP is its ability to ingest information from multiple sources that are relevant to icing and integrate them so that their strengths are maximized and their weaknesses are minimized. For each input dataset, CIP developers have leveraged research results and practical forecasting experience to understand their characteristics so that their use can be optimized. In-flight icing forecasters from the National Center for Atmospheric Research (NCAR) began using the GDCPs during the winter of 2003-04 and have built a substantial experience base with them through numerous flight campaigns. While much success has been achieved through the use of the GDCPs, comparisons between some GDCPs and in-situ observations from research aircraft have yielded only marginal results ${ }^{6}$. Practical experience with GDCPs has revealed several features in the LWP, REFF and PHASE fields that need to be considered when attempting to apply them as forecasters, and especially as part of a an automated system, such as CIP. These will be explored in this paper, though the examination of a variety of icing situations that were sampled by instrumented aircraft during two flight seasons.

\section{Aircraft and satellite data}

During the winter and spring of 2004 and 2005, the NASA Glenn Research Center's Twin Otter research aircraft ${ }^{7}$ flew within icing clouds, primarily over Ohio. The Twin Otter carried probes that measured state and microphysical parameters, including air temperature, liquid water content (LWC) and drop size. LWC was provided by the CSIRO ("King") ${ }^{8}$ and Nevzorov probes. While primarily used to determine the size of relatively small (less than $100 \mu \mathrm{m}$ diameter) particles, the FSSP also provided reasonable estimates of liquid water content and median volumetric diameter when small liquid water drops dominated the clouds that were sampled. Two-dimensional

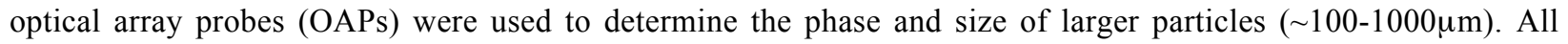
observations are averaged over 4-km flight legs to match the scale of a single satellite pixel from the GDCPs. Aircraft data were matched to the closest satellite time, with a maximum time difference of $15 \mathrm{~min}$. allowed. Only daytime imagery from the $12^{\text {th }}$ Geostationary Operational Environmental Satellite (GOES-12) was used for these comparisons ${ }^{6}$. The analyses primarily use half-hourly $4-\mathrm{km}$ pixel-level radiances measured at wavelengths $0.65,3.9$ and $11 \mu \mathrm{m}$. The brightness temperature at $11 \mu \mathrm{m}(\mathrm{T} 11)$ is used to estimate cloud top temperature.

\section{Icing Events}

A variety of icing events was sampled during the winters of 2004 and 2005, ranging from fairly widespread and reasonably consistent to highly variable. Features of both are described below, and their implications are discussed in a later section.

\section{A. 16 February 2005}

One icing event that had reasonably consistent features on the scale of $\sim 100 \mathrm{~km}$ was sampled by the Twin Otter between 1510 and 1715 on 16 February 2005 (all times are in UTC). NCAR forecasters specifically used the GDCPs 
to help guide the aircraft, suggesting that it be flown toward areas with relatively large values of LWP ${ }^{9}$ GDCP imagery from 1545 indicated the presence of a swath of fairly consistent stratus clouds near Cleveland, Ohio (KCLE; Fig. 2), with SLW diagnosed at their top and cloud top temperatures near $-10^{\circ} \mathrm{C}$. LWP and REFF were 300-600 $\mathrm{gm}^{-2}$ and 9-13 $\mu \mathrm{m}$, respectively. The mesoscale gradients in the LWP field proved to be quite meaningful. LWC gradually increased from $\sim 0.1$ to $\sim 0.4 \mathrm{gm}^{-3}$ as the aircraft flew across a LWP gradient where values increased from $\sim 200$ to $\sim 450 \mathrm{gm}^{-2}$. The lowest LWCs were found within areas of low LWP just to the northwest of KCLE.

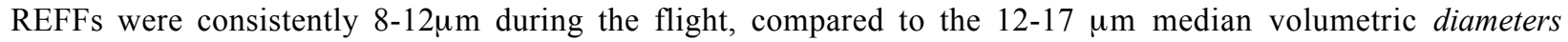
(MVDs) measured by the FSSP. For a modified gamma distribution of drops, the MVD is typically $2 / 3$ of the effective diameter. Thus, the range in MVD here would roughly correspond to REFFs between 9 and $13 \mu \mathrm{m}$.

This case represents a relatively straightforward situation for satellite-based products. Only a single layer of fairly uniform stratiform clouds was present, with no obscuration by higher-level clouds. Aircraft data indicate that the upper portion of the clouds was completely dominated by small, supercooled liquid water drops. This is the simplest of all icing situations. Yet, even these relatively simple icing clouds have gradients and transition zones, such as those that were present to the east of KCLE (Fig. 2). Such aspects will be examined in the cases that follow. Many icing situations are more complex than the clouds flown on 16 February, featuring partial or total obscuration of supercooled liquid layers by ice-crystal dominated clouds above, and significant smaller-scale variability in microphysical content. Such cases pose additional challenges for the GDCPs and some examples are described below.

\section{B. 22 February 2005}

Low-altitude, stratiform icing clouds are commonly obscured by higher cloud layers. The higher layers sometimes contain icing conditions, but are often quite cold and glaciated. While icing conditions can be present in cloud layers below, only the colder, upper deck is often visible to the satellite and ice crystals are diagnosed. Such was the case on 22 February 2005, when the NASA Twin Otter flew within an area of SLW clouds that extended across Ohio. At $\sim 2010$, the Twin Otter climbed though three mixed-phase cloud layers with LWC between 0.25 and $0.5 \mathrm{gm}^{-3}$ as they flew toward the southwest. The upper-most of these layers was between 3 and 4km MSL, had cloud top temperatures near $-13^{\circ} \mathrm{C}$, LWC near $0.3 \mathrm{gm}^{-3}$ and included some stellar and dendritic crystals. The crew noted the presence of thin, broken clouds above this layer, but they were not worthy of sampling. It was the leading edge of a swath of higher, colder $\left(-20\right.$ to $\left.-25^{\circ} \mathrm{C}\right)$ clouds, diagnosed as "ice clouds", that were quickly moving in from the northwest, obscuring the liquid water layers below from satellite view (Figs. 3, 4). The Twin Otter crew chose to descend back into the lowest of the SLW layers below for the remainder of the flight, because it had the maximum LWC (near $0.5 \mathrm{gm}^{-3}$ ) and was found to be free of ice crystals farther to the southwest of KCLE.

While the $-13^{\circ} \mathrm{C}$, upper-most icing clouds sampled by the Twin Otter on climbout were partially obscured by the thin broken layer above, they were well exposed to space to the south and southeast of KCLE. LWPs were highly variable there and along the edge of the cold, upper cloud layer. They were mostly on the order of 400-700 gm near KCLE (Fig. 3). The LWPs in the well-exposed areas near KCLE during this portion of the flight were in reasonable agreement with the in-situ observations made at similar temperatures, given the rough relationship between LWP and cloud top LWC described earlier.

REFFs were quite variable (between 10 and $20 \mu \mathrm{m}$ ) along the edge of the high clouds, most likely the result of the relatively thin layer of ice crystals overlying the mixed-phase and water-dominated decks below. In this case, reflected near-infrared radiances from the mixed-phase layer below would be attenuated by the ice crystals in the thin, broken upper layer above, causing the observed radiances to appear to be from large drops. Such a signal could be incorrectly interpreted as the presence of supercooled large drops (SLD). The REFFs were mostly near $8 \mu \mathrm{m}$ in the well-exposed areas, but they could not be readily compared to the Twin Otter's FSSP-derived MVDs, since they were contaminated by the simultaneous presence of ice crystals.

Relatively widespread, smooth fields like those evident on 16 February were present over southeastern Ohio and southwestern Indiana on 22 February. Forecaster experience and the case studies that follow indicate that reasonable matches between aircraft and satellite datasets are not always found within areas of variable LWP and REFF around the edges of obscuring, upper-cloud layer. The use of LWP and REFF in such environments must be handled with care. When considering the practical application of GDCPs for use either in manual nowcasting or for ingest into automated systems such as CIP, it must be acknowledged that such overlying cloud situations can make the assessment of the characteristics of the cloud layer(s) beneath quite difficult. In the case of a small-scale (less than about $200 \mathrm{~km}$ across) obscuring upper cloud deck with relatively consistent satellite fields on either side, one may be able to reasonably expect that the lower cloud deck will have similar features where it has been obscured ${ }^{10}$. However, when the features of the exposed portion of the cloud are spotty and/or inconsistent, as they were on 22 
February, confidence in them and interpolation of their values would be diminished. Furthermore, if information from other sources shows that conditions within the obscured portion of the cloud may be different than those that are not obscured, such interpolation may be highly inappropriate.

At 2115, the Cleveland NEXRAD revealed that significant precipitation was falling in some areas beneath some portions of the upper cloud layer (Figs. 4, 5). It was not evident in the areas where only the lower, warmer-topped cloud layer was present. This critical information strongly implies that the upper cloud layer was seeding some portions of the lower cloud layers with ice crystals, which can dramatically decrease their liquid water content. NCAR forecasters guided the Twin Otter to the south of the echoes, keeping them within the portion of the obscured lower layer that was dominated by SLW. Ice-dominated, low LWC conditions were later found when the Twin Otter flew through the areas with significant radar echoes as they returned to land at KCLE near 2200. The additional information from NEXRAD indicated that interpolation of the GDCPs to some portions of the lower deck would not have been appropriate. In some cases where such echoes are not present, interpolation may be appropriate, such as toward the southern end of the obscured area on this day. Additional information may be gleaned from surface observations of precipitation and perhaps ceiling height and even visibility.

While the agreement between the in-situ observations and nearby GDCP values was reasonable for the highest cloud deck sampled by the Twin Otter on this day, some important questions are raised by this case: 1) How "clean" or "smooth" does a signal have to be to be acceptable for use, both locally and for interpolation? 2) Should the rather low, but smooth looking values over southeastern Ohio be interpolated, rather than the spottier (and in this case, roughly correct) values around KCLE? 3) When using radar and other fields to determine the appropriateness of the use of interpolation schemes, what features and/or thresholds should be used? 4) Can confidence information from these and other fields provide a rough estimation of the usefulness of GDCPs in such situations?

\section{27 January 2004}

This case provides a second example of a multiple layer situation, where the low-altitude, SLW-dominated cloud layer was partially obscured by a higher-altitude, ice-crystal dominated cloud layer. Most of the sampled clouds were exposed to space, allowing for an assessment of their characteristics by satellite. However, there are other aspects of this case that set it apart from the previous case. First, the observed liquid water contents were extremely high for wintertime stratocumulus, with values between 0.9 and $1.2 \mathrm{gm}^{-3}$ consistently observed near $1600 \mathrm{~m}(\sim 5,250$ $\mathrm{ft})$ MSL. The second aspect was the vertical profile of SLW, which was maximized $\sim 200 \mathrm{~m}(600 \mathrm{ft})$ below cloud top (1800m; Fig. 6), then gradually decreased with height through an isothermal layer, reaching zero at cloud top. The FSSP-measured MVD followed a similar pattern, increasing to a maximum near $18 \mu \mathrm{m}$, where some SLD in the form of drizzle was present, and then decreasing to $\sim 10 \mu \mathrm{m}$ near cloud top, where cloud-sized drops were more dominant. Normally the profile within a wintertime stratocumulus layer that is dominated by small water drops has a "wedge" appearance to it, with the SLWC and MVD gradually increasing to cloud top, then abruptly going to zero at the interface with a stable layer and sub-saturated air above. If the lapse rate deviates from moist adiabatic within the cloud layer, breaks develop within it or significant precipitation falls from it, this wedge profile is often not realized. Though it is assumed to be common in some icing-detection systems, many icing clouds have much more complex vertical structures. Those present over KCLE on 27 January provide one such example.

What makes that aspect of particular interest here is the fact that a satellite sensor using visible and infrared detectors can only see so far down into a cloud, based on a given cloud's microphysical properties and thus, its optical depth. If the cloud is optically dense at these wavelengths, as is the case with a moderate or high water content, small-drop dominated cloud, the depth below cloud top from which the signal emanates is decreased. With the maximum SLW and drop size found $\sim 200 \mathrm{~m}$ below cloud top, did the satellite observe the most intense part of this icing cloud? After its initial takeoff at 1600, the Twin Otter flew within clouds just to the south of KCLE, then spent most of the flight sampling to the northwest and northeast of KCLE. All of these areas were well exposed to the satellite through $\sim 1700$. At 1615, the phase product indicated an area of ice cloud to the east and northeast of KCLE, while the LWP product had a $\sim 75-\mathrm{km}$ wide swath of $600-1000 \mathrm{gm}^{-2}$ along its western edge, where the Twin Otter was flying (Fig. 7). REFF values were on the order of 7-11 $\mu \mathrm{m}$ there, except for some higher values in a few small areas along the back edge of the upper, ice-dominated cloud, and some larger areas to the south and west of KCLE. The latter features were also small in scale, but had a less noisy appearance than those observed on 22 February 2005. The LWP and REFF values diagnosed by the satellite on 27 February 2004 were very similar to those found in the cases discussed earlier, where the relatively low, in-situ measured water contents were maximized near cloud top and were similar to those observed near cloud top on this day. Thus, it appears that the satellite retrieval was dominated by the relatively low LWC, small drop portion of this cloud, where SLD was not evident. The LWCs and MVDs near cloud top were one-quarter to one-half the magnitude of those found just a few hundred meters below, where the greatest icing hazard was present. 


\section{3 February 2005}

The icing clouds were quite inconsistent on this day, and it was reflected in the GDCPs. The Twin Otter flew southeast from KCLE to sample what initially appeared to be locally deep, but somewhat irregular clouds. As usual, flight decisions were made quite early in the morning, without the availability of visible satellite imagery or daytime GDCPs. Infrared imagery, combined with surface observations and a few pilot reports indicated that regions of significant SLW might have been present within and around swaths of $-10^{\circ} \mathrm{C}$ clouds in that direction. Upon initial takeoff at 1334, a moist adiabatic layer with LWC exceeding $0.3 \mathrm{gm}^{-3}$ and cloud top temperature near $-4^{\circ} \mathrm{C}$ was found from just above the surface to $\sim 500 \mathrm{~m}(\sim 1500 \mathrm{ft})$ MSL. While this layer posed an icing threat to aircraft taking off and landing at Cleveland, it was too low for practical sampling, due to minimum vectoring altitude limitations. Continuing the ascent, the Twin Otter identified at least five distinct cloud layers between the surface and $4 \mathrm{~km}$ $(\sim 12,000 \mathrm{ft}) \mathrm{MSL}$, with SLW peaks of $0.05,0.10,0.20,0.15$ and $0.10 \mathrm{gm}^{-3}$ (Fig. 8). Adequate illumination for daytime calculations of LWP first became available as of the 1415 satellite image, so a direct comparison between the GDCPs and the in-situ measurements made during this climb was not made.

Only variable icing was found during the flight, with the "best" icing found between 1402 and 1413, within mixed phase conditions to the southeast of Youngstown, Ohio (KYNG). These clouds had highly variable LWC between 0 and $0.4 \mathrm{gm}^{-3}$ at $-6^{\circ} \mathrm{C}$ near $2700 \mathrm{~m}(8,000 \mathrm{ft})$. FSSP MVDs did not provide meaningful estimations of drop size because of the simultaneous presence of ice crystals. The LWP field showed southwest-to-northeast oriented striations, with values ranging from near 0 to more than $800 \mathrm{gm}^{-2}$, interspersed with a few patches diagnosed as "ice cloud" (Fig. 9). Examination of the visible satellite image hints at the multi-layer situation that was present, with the high LWP values occurring along the southeastern edges of some of these southwest-northeast swaths of the higher, cooler (about $-13^{\circ} \mathrm{C}$ ) clouds. The early morning, wintertime sun illuminated the southeastern edges of these clouds particularly well, making them appear especially bright. This was particularly evident with a broad southwestnortheast oriented swath of relatively high clouds over northwestern Ohio, where a wide stripe of LWP values exceeding $800 \mathrm{gm}^{-2}$ was evident along the east side of some even deeper, colder-topped $\left(<-20^{\circ} \mathrm{C}\right)$ clouds that were diagnosed as "ice phase". This rather strong feature persisted through 1515 (Fig. 10) until the upper clouds moved eastward and dissipated, revealing relatively low LWP (200-500 $\left.\mathrm{gm}^{-2}\right)$ values associated with the lower liquid water layer(s) below at 1545 (Fig. 11). Without in-situ measurements in the upper cloud layer, it is impossible to say whether significant SLW existed there, but no icing was reported as these clouds passed through the busy airspace near Detroit.

The striations over northeastern Ohio also persisted through at least 1445 (not shown), with patchy, wellilluminated areas and anomalously high LWP still evident at 1515 . Though the features over this area appeared to be more consistent by 1545, small areas of high LWP were still present around the edges of somewhat higher clouds. As with previous cases, their meaning was somewhat unclear. Anomalously low LWP values and apparently incorrect indications of "clear skies" were diagnosed within shadowed areas just to the northwest of the swaths of higher clouds over central Ohio. Though the trained eye is capable of identifying and perhaps correcting for these features, automated systems will need to be developed to handle them. Sun angle, as well as the presence of local gradients in other fields, such as the infrared channel, may provide some clues and a sense of confidence (or lack thereof) in the diagnosed values.

\section{Discussion and Conclusions}

The cases described above demonstrate how icing clouds can occur on many different scales, both horizontally and vertically, with wide variability in exposure to satellite view. Broad areas of uniform icing conditions do occur on occasion, but represent the exception rather than the rule. It is very common for icing conditions to have significant variability on the mesoscale and to occur in multi-layer situations, with some layers partially or completely obscured from the satellite. Gradual, horizontal variations are most clearly evident in satellite-derived fields, including GDCPs, when a single-layer, water-dominated cloud layer is present and well exposed to space, such as over Cleveland on 16 February 2005. Gradients have proven meaningful in these situations and the application of GDCPs for icing diagnosis is quite robust, at least in a two-dimensional sense.

Determination of the proper location and distribution of SLW in the vertical provides another challenge, however. First and foremost, what do LWP retrievals that are heavily weighted by cloud top characteristics imply about the liquid water content below cloud top? Some researchers assume that a "wedge" shape LWC profile will be present, as a first guess. Even if this guess is correct and a cloud base height was known (as it is in CIP), the water may be distributed at the wrong altitudes. GDCP and CIP cloud top height estimates have been shown to be too high by $1 \mathrm{~km}$ or more in some cases ${ }^{11}$. Experience has shown that this error tends to be particularly large for warm-topped, stratiform cloud layers capped by inversions, which are fairly common. Using the wedge profile, the 
maximum liquid water content would be decreased because the water would be distributed over a much greater depth than that of the real cloud. It would also be placed at a cloud-free altitude where no icing would occur, then be tapered down to lesser values at the real cloud top, where the maximum threat actually exists. Even if cloud top height estimates were perfect, the cases above clearly demonstrate that the assumption of a wedge profile is a poor one. Icing clouds commonly contain subtle features that cause the worst icing to be in locations other than those where the standard profiles might place them. Such features were particularly evident on 27 January 2004 and both 3 and 22 February 2005. A close examination of stability and moisture structures in the vertical is crucial to determining the altitude and intensity of icing layers. While numerical model fields, like those ingested into CIP, can provide clues, subtle changes in these parameters are often smoothed or missed altogether.

All of these issues are present for the simplest of all situations, a single-layer, all-water, small-drop icing cloud that is well exposed to space. As demonstrated in the cases above, many icing situations are far more complex, with partial or complete obscuration of icing layers, the presence of multiple liquid water layers, strong gradients, edge effects, transitions in particle phase and size, and solar angle. Given all of these complexities, the interpretation of satellite-based assessments of icing requires great care when done manually. It will require great caution when disseminated to untrained users or when applied in an automated fashion, especially as a stand-alone product.

As described earlier, GDCPs are being considered for future integration into CIP, including the new CIP Severity field ${ }^{4,5}$. While this concept has been demonstrated two-dimensionally for the 16 February 2005 case $^{5}$, a three-dimensional application will prove to be rather complex. However, there is reason for hope. Because CIP ingests additional observations from surface stations, a radar mosaic, pilot reports and a lightning network in addition to other satellite fields and numerical model grids, the GDCPs can be placed into a wealth of context. Surface observations provide direct measurements of the lowest cloud base and information on the presence of multiple cloud layers, in some cases. The occurrence of precipitation and its type is also provided from surface observations in conjunction with 2-D radar mosaics. These data can help to bound the cloud and determine whether large particles and/or ice phase may be present at some level within them. They may also provide information on whether interpolation and/or extrapolation of GDCP values to clouds obscured from satellite view is appropriate. Placed in the context of model-based profiles of temperature, moisture and even winds, the surface and radar observations may also help with the estimation of the vertical distribution of SLW. Recent efforts on improving cloud base estimates ${ }^{4}$ are going to be applied and tested at cloud top, perhaps leading to improvements in bounding a given cloud layer. More accurate cloud base and top estimates, used in conjunction with recently developed 3-D mosaics of radar reflectivity ${ }^{12}$, may serve to further improve the vertical location and distribution of SLW.

Techniques are being tested to identify when the satellite-observed scene contains thin cirrus above SLW clouds to help determine where false readings of SLD occur and to aid in the interpolation of cloud properties when an ice layer obscures the SLW layer ${ }^{10,13}$. Unfortunately, the most robust multi-layered detection techniques currently use $12-\mu \mathrm{m}$ radiances, which are only measured by the western GOES satellites (e.g. GOES-10). However, the new series, GOES-R, will return the $12-\mu \mathrm{m}$ channel to service, along with a number of other new wavelengths that are helpful for interpreting cloud types.

Overall, while they are not a panacea for in-flight icing, the GDCPs provide another valuable piece to the puzzle. As has been the case with any icing tool that CIP developers have assessed to date, the GDCPs have strengths and weaknesses. When used in the proper context, they are highly valuable to forecasters and have solid promise as an ingredient in CIP. A great deal of work lies ahead to realize this promise, but potential paths to success are evident.

\section{Acknowledgments}

The authors would like to than the NASA Twin Otter crew for continuing to provide invaluable data from samples of in-flight icing environments over the southern Great Lakes area. Thanks also go to the GDCP team at NASA Langley for providing NCAR forecasters with a special web page of their real-time products, focusing on the Cleveland area. This project is supported by the NASA Applied Sciences Program and the NASA Aviation Safety and Security Program through the NASA Advanced Satellite Aviation-weather Products (ASAP) project. NCAR is sponsored by the National Science Foundation. This research is in response to requirements and funding by the Federal Aviation Administration (FAA). The views expressed are those of the authors and do not necessarily represent the official policy of position of the FAA. 


\section{References}

${ }^{1}$ Minnis P., W. L. Smith, Jr., L. Nguyen, M. M. Khaiyer, D. A. Spangenberg, P. W. Heck, R. Palikonda, B. C. Bernstein, and F. McDonough, 2004a: A real-time satellite based icing detection system. Proc. $14^{\text {th }}$ Intl. Conf. Clouds and Precipitation, Bologna, Italy, 18-23 July.

${ }^{2}$ Minnis P., L. Nguyen, W. L. Smith, Jr., M. M. Khaiyer, R. Palikonda, D. A. Spangenberg, D. R. Doelling, D. Phan, G. D. Nowicki, P. W. Heck, and C. Wolff., 2004b: Real-time cloud, radiation, and aircraft icing parameters from GOES over the USA. Proc. $13^{\text {th }}$ Conf. on Satellite Oceanography and Meteorology, Norfolk, VA, 20-24 September.

${ }^{3}$ Bernstein, B.C., F. McDonough, M.K. Politovich, B.G. Brown, T.P. Ratvasky, D.R. Miller, C.A. Wolff, and G. Cunning, 2005: Current icing potential (CIP): Algorithm description and comparison with aircraft observations. J. Applied Met., 44, $969-$ 986.

${ }^{4}$ Bernstein, B.C., F. McDonough, C.A. Wolff, M.K. Politovich, G. Cunning, S. Mueller and Stephan Zednik, 2006: The new CIP icing severity product. Proc. $12^{\text {th }}$ Conf. on Aviation, Range and Aerospace Meteorology, Atlanta GA, 29 January - 2 February. Available on CD-from from the Amer. Met. Soc.

${ }^{5}$ Haggerty, J.A., G. Cunning, B. Bernstein, M. Chapman, D. Johnson, M. Politovich, C. Wolff, P. Minnis, R. Palikonda, 2005: Integration of advanced satellite cloud products into an icing nowcasting system. WWRP Symposium on Nowcasting and Very Short Range Forecasting, Toulouse, France, 5-9 September.

${ }^{6}$ Wolff, C.A. and J.A. Haggerty, 2006: Point comparisons of research aircraft data to GOES-derived cloud products. Proc. $12^{\text {th }}$ Conf. on Aviation, Range and Aerospace Meteorology, Atlanta GA, 29 January - 2 February. Available on CD-from from the Amer. Met. Soc.

${ }^{7}$ Miller, D., T. Ratvasky, B. Bernstein, F. McDonough and J.W. Strapp, 1998: NASA/ FAA/NCAR supercooled large droplet icing flight research: summary of winter 96-97 flight operations. $36^{\text {th }}$ Aerospace Science Meeting and Exhibit, AIAA 98-0557, Reno NV, American Institute of Aeronautics and Astronautics, $20 \mathrm{pp}$.

${ }^{8}$ King, W.D., D.A. Parkin, and R.J. Handsworth, 1978: A hot-wire liquid water device having fully calculable response characteristics. J. Appl. Meteor., 17, $1809-1813$.

${ }^{9}$ Wolff C. A., B. C. Bernstein, and F. McDonough, 2006: Nowcasting aircraft icing conditions using GOES-derived cloud products. Proc. $12^{\text {th }}$ Conf. on Aviation, Range and Aerospace Meteorology, Atlanta GA, 29 January - 2 February. Available on CD-from from the Amer. Met. Soc.

${ }^{10}$ Minnis, P., M. Khaiyer, Y. Yi, S. Sun-Mack, R. Palikonda, D. Spangenberg, and J. Huang, 2005: Developing a 3-D cloud product over the ARM sites using GOES data. Proc. $15^{\text {th }}$ ARM Sci. Team Mtg., Daytona Beach, FL, March 14-18.

${ }^{11}$ Chapman, M., A. Holmes, and C. Wolff, 2005: Verification of aviation icing algorithms from the second alliance icing research study. WWRP Symposium on Nowcasting and Very Short Range Forecasting, Toulouse, France, 5 - 9 September.

${ }^{12}$ Elmore, K.L., C.J. Kessinger, T.L. Schneider and D.J. Smalley, 2004: The AWRP's Advanced Weather Radar Products Development Team. 11th Conference on Aviation, Range and Aerospace Meteorology, Hyannis MA, 11-14 October, Amer. Met. Soc., Boston. Available on CD from the AMS.

${ }^{13}$ Pavlonis, M.J. and A. K. Heidinger, 2004: Daytime cloud overlap detection using AVHRR and VIIRS. J. Appl. Meteorol., 43, 762-778. 


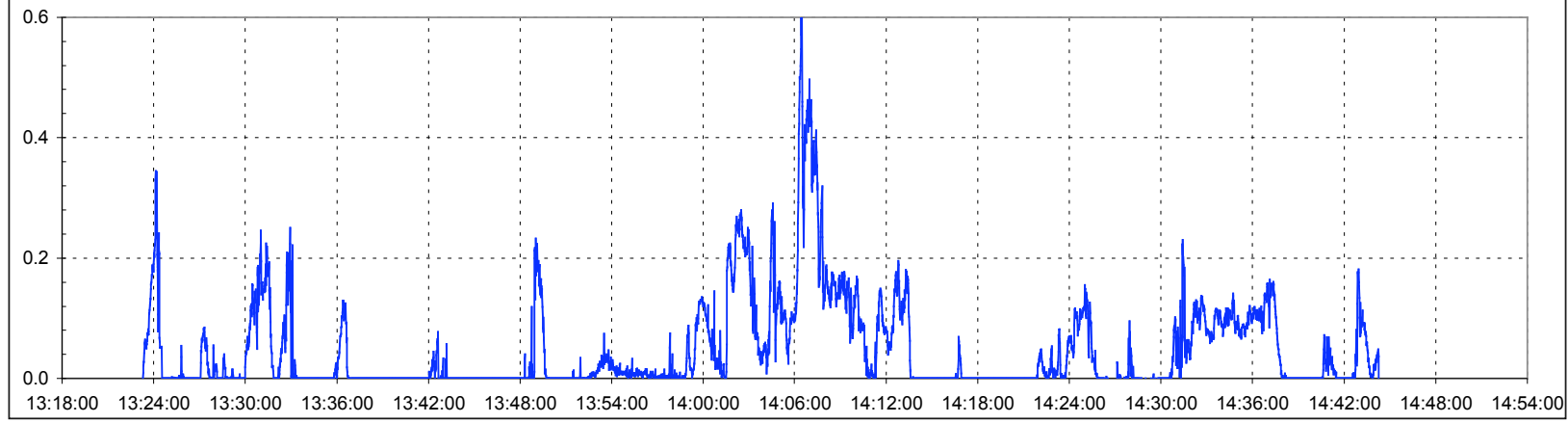

Fig. 1 - Time series of Twin Otter King probe LWC from 3 February 2005. 

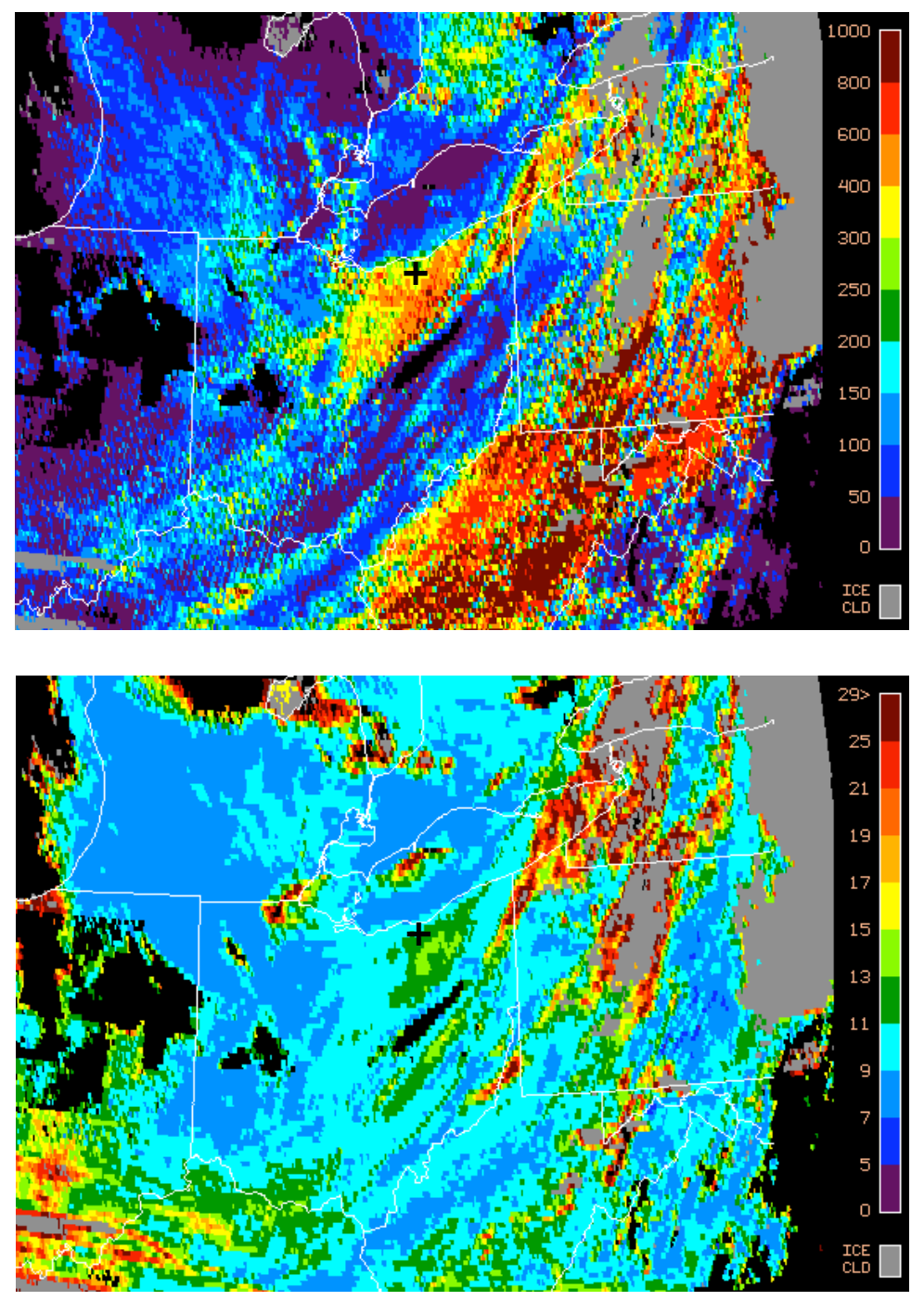

Fig. 2 - GDCP diagnoses of LWP $\left(\mathrm{gm}^{-2}\right)$ and REFF $(\mathrm{mm})$ for 1545 on 16 February 2005 . The location of KCLE is marked with a "+". 

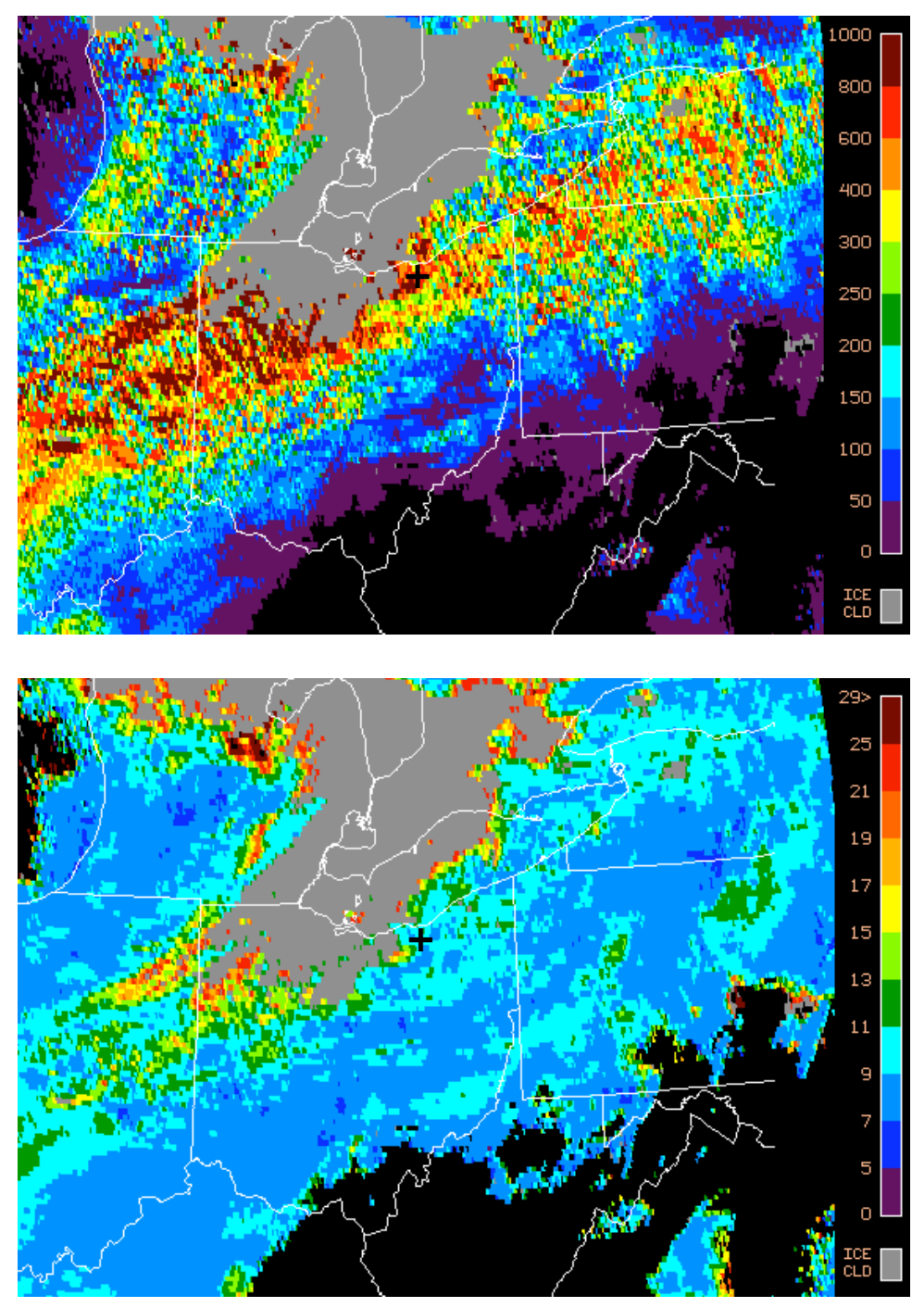

Fig. 3. Same as Fig. 2, but for 2015 on 22 February 2005. 

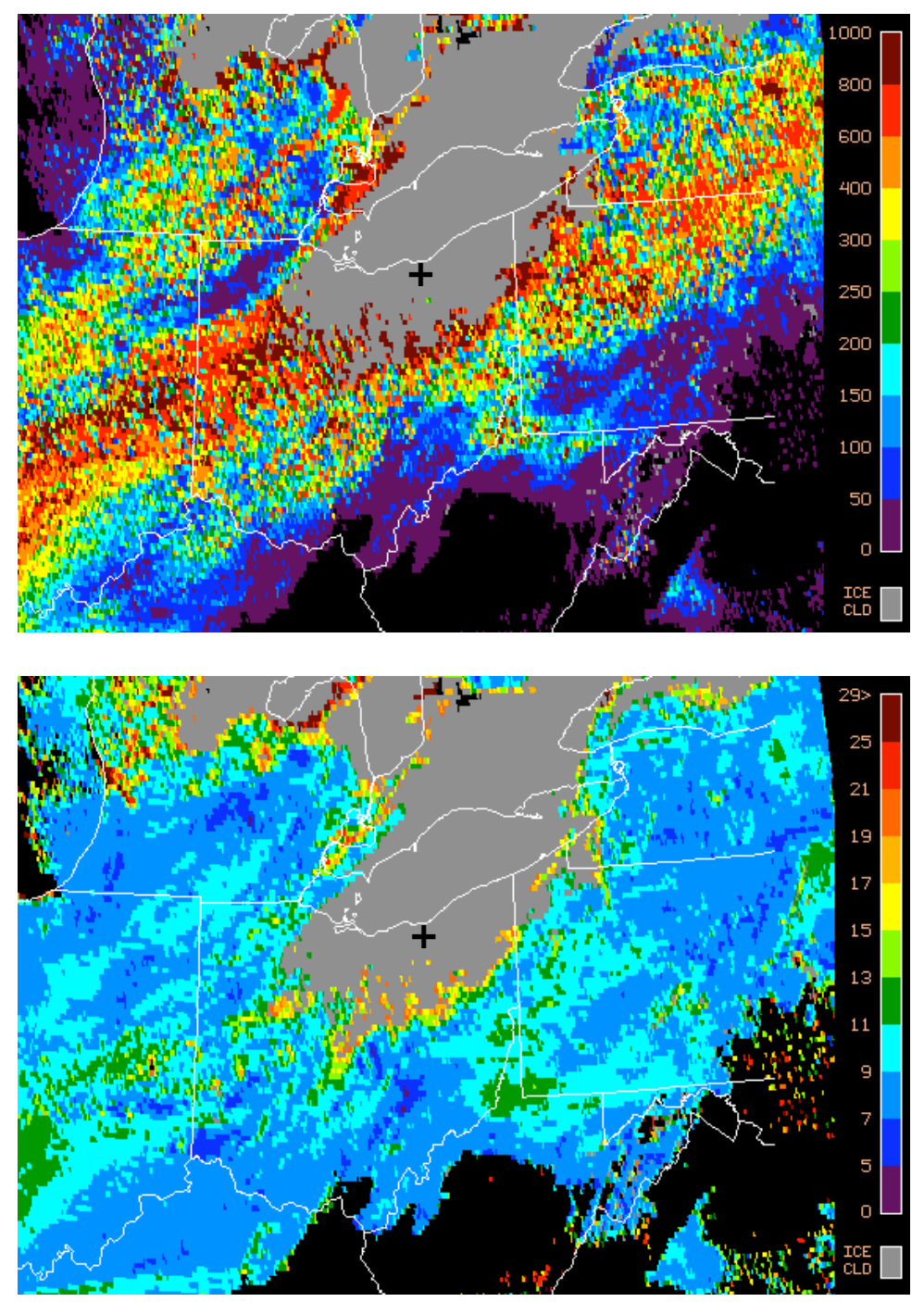

Fig. 4 - Same as Fig. 2, but for 2115 on 22 February 2005. 


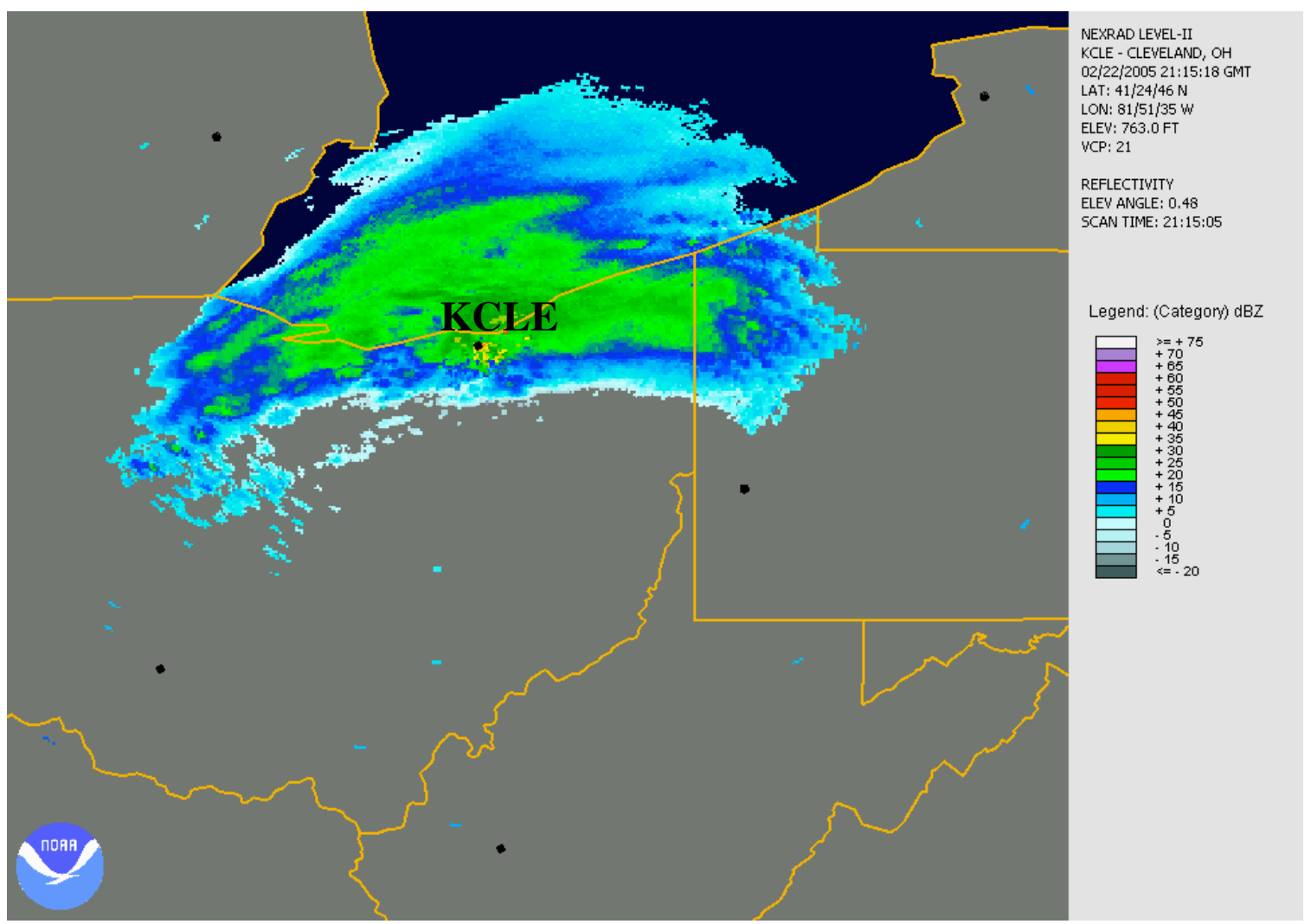

Fig. 5 - KCLE NEXRAD $0.5^{\circ}$ elevation reflectivity for 2115 on 22 February 2005. 

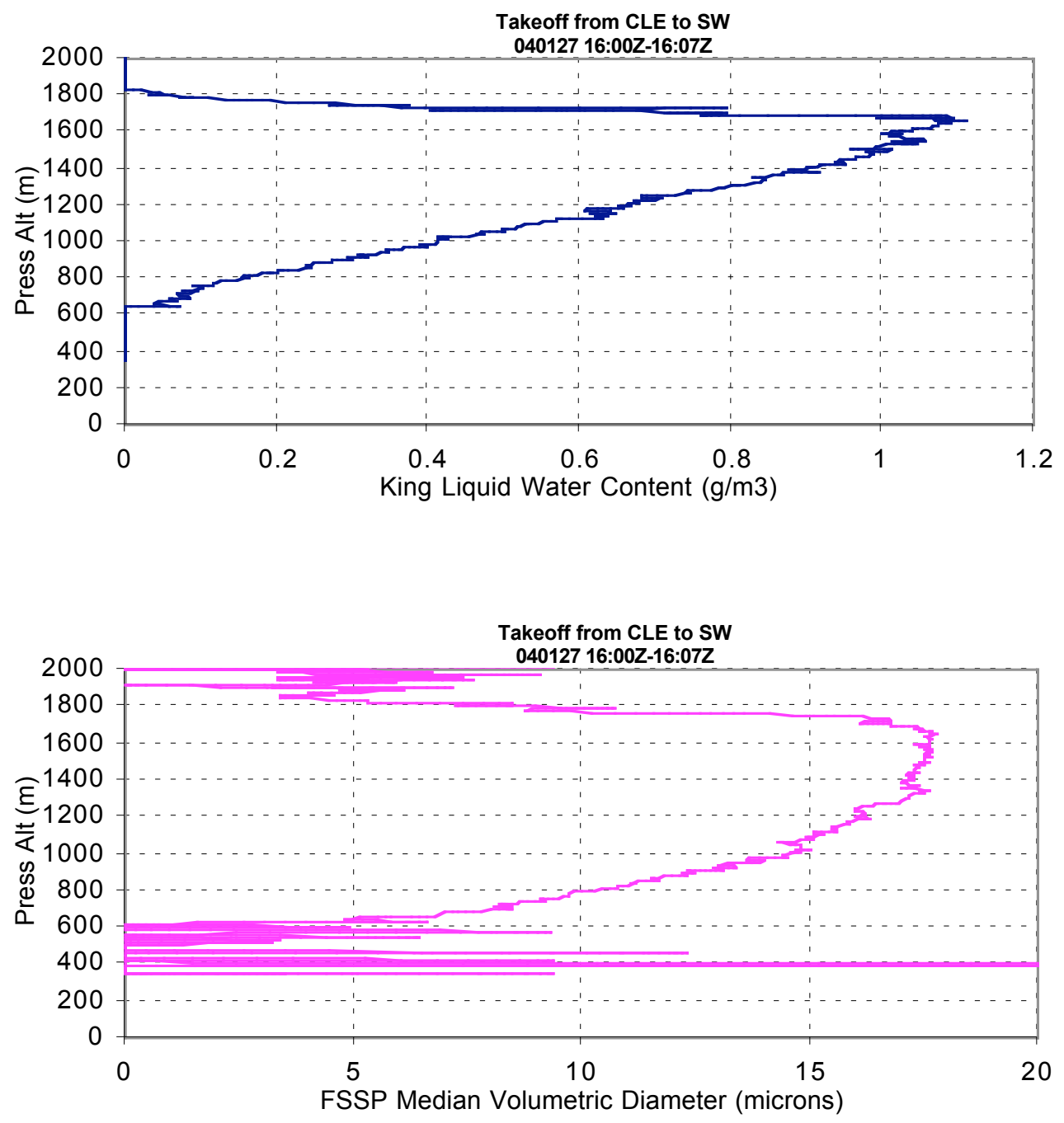

Fig. 6 - Profiles of King probe LWC and FSSP MVD for climb over KCLE on 27 January 2004. 

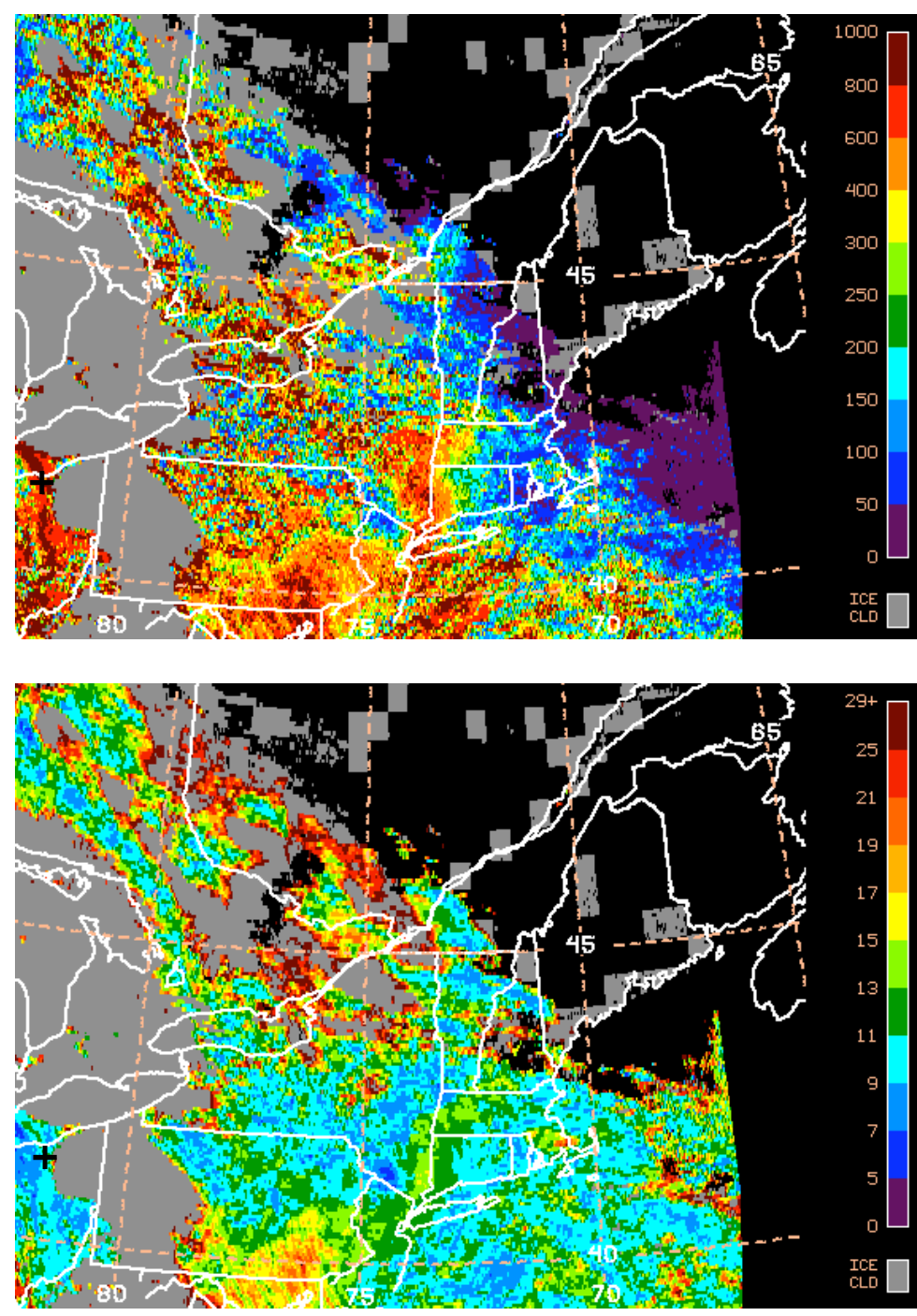

Fig. 7 - Same as Fig. 2, but for 1615 on 27 February 2004. 


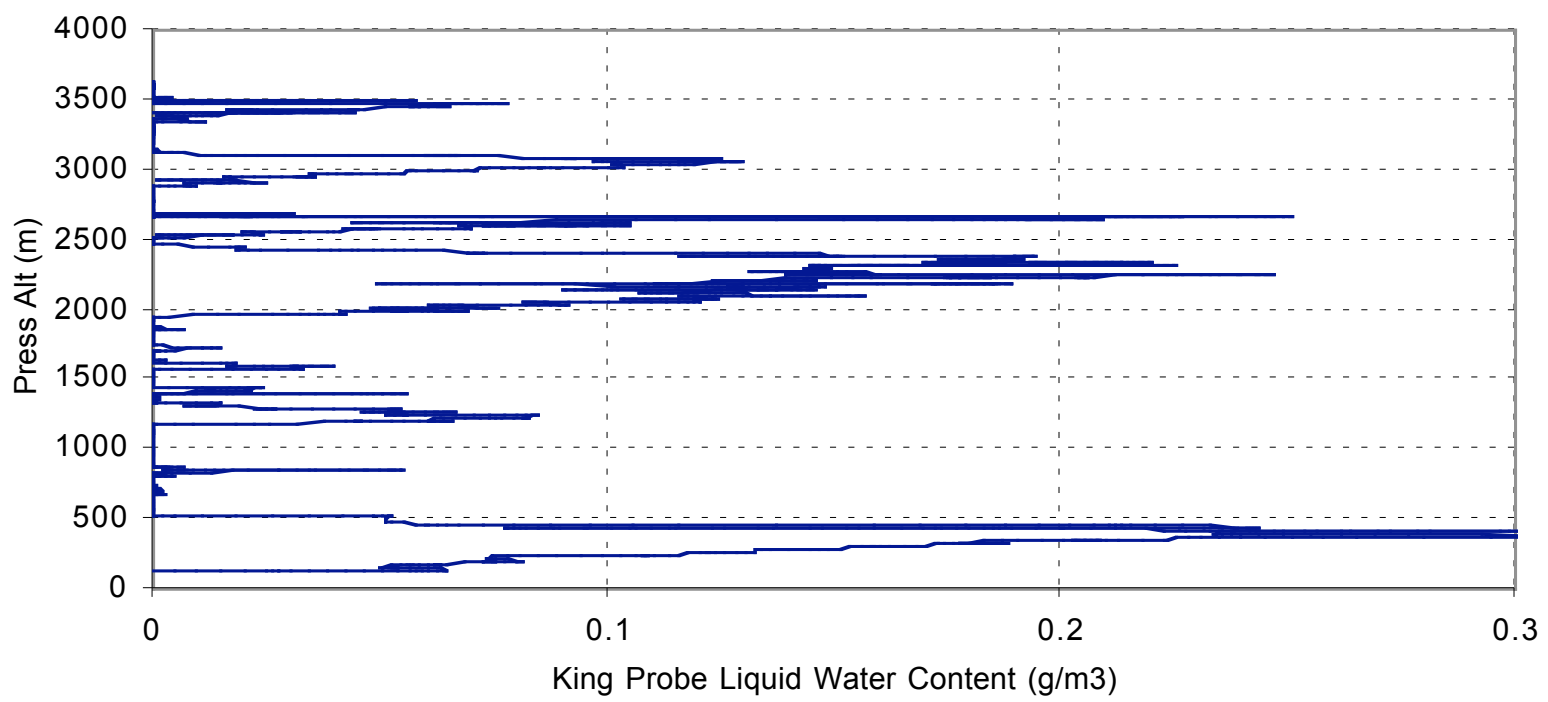

Fig. 8 - Vertical profile of King probe LWC for climb over KCLE on 3 February 2005. 

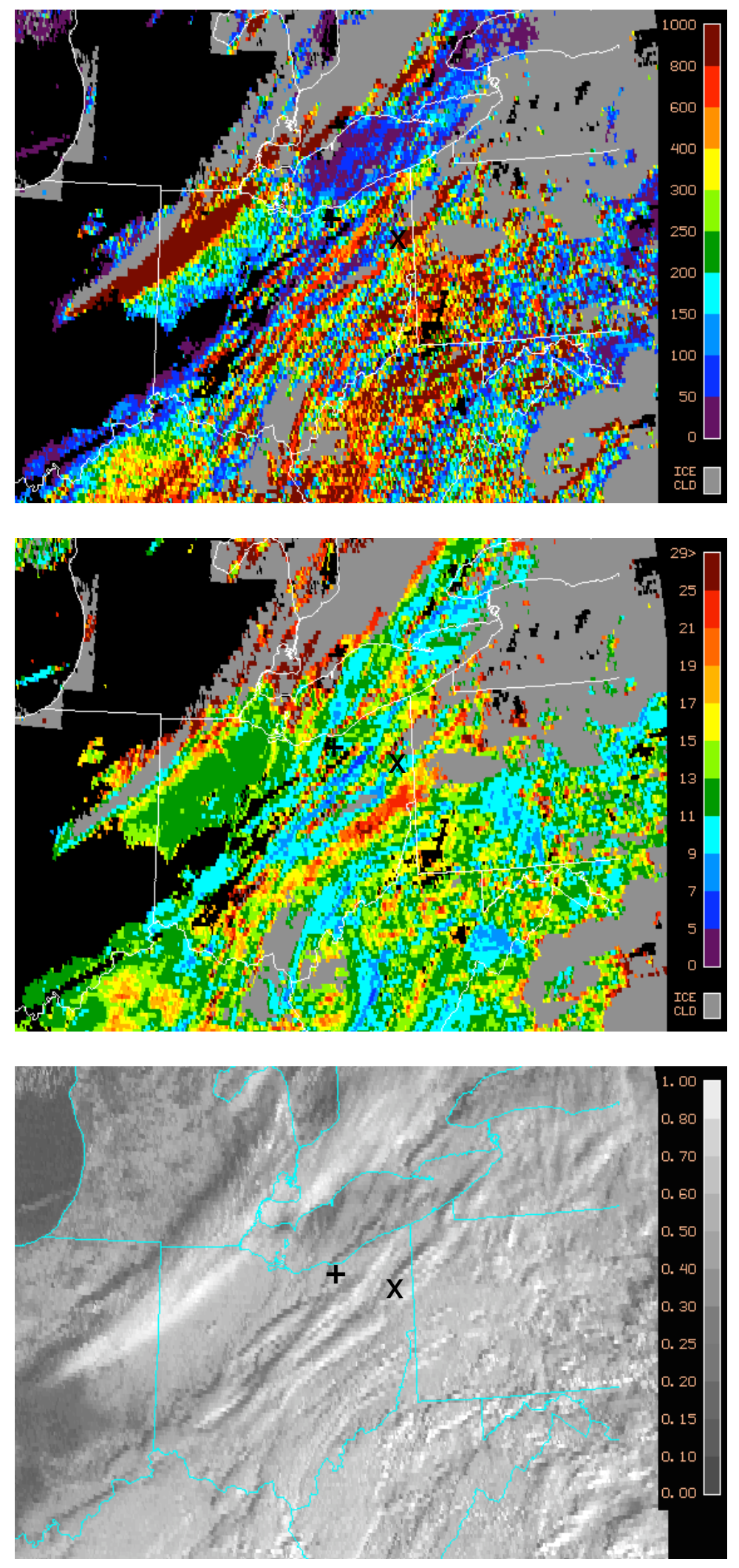

Fig. 9 - Same as Fig. 2, but for 1415 on 3 February 2005, with a visible image added. The location of KYNG (Youngstown, Ohio) is marked with an " $x$ ". 

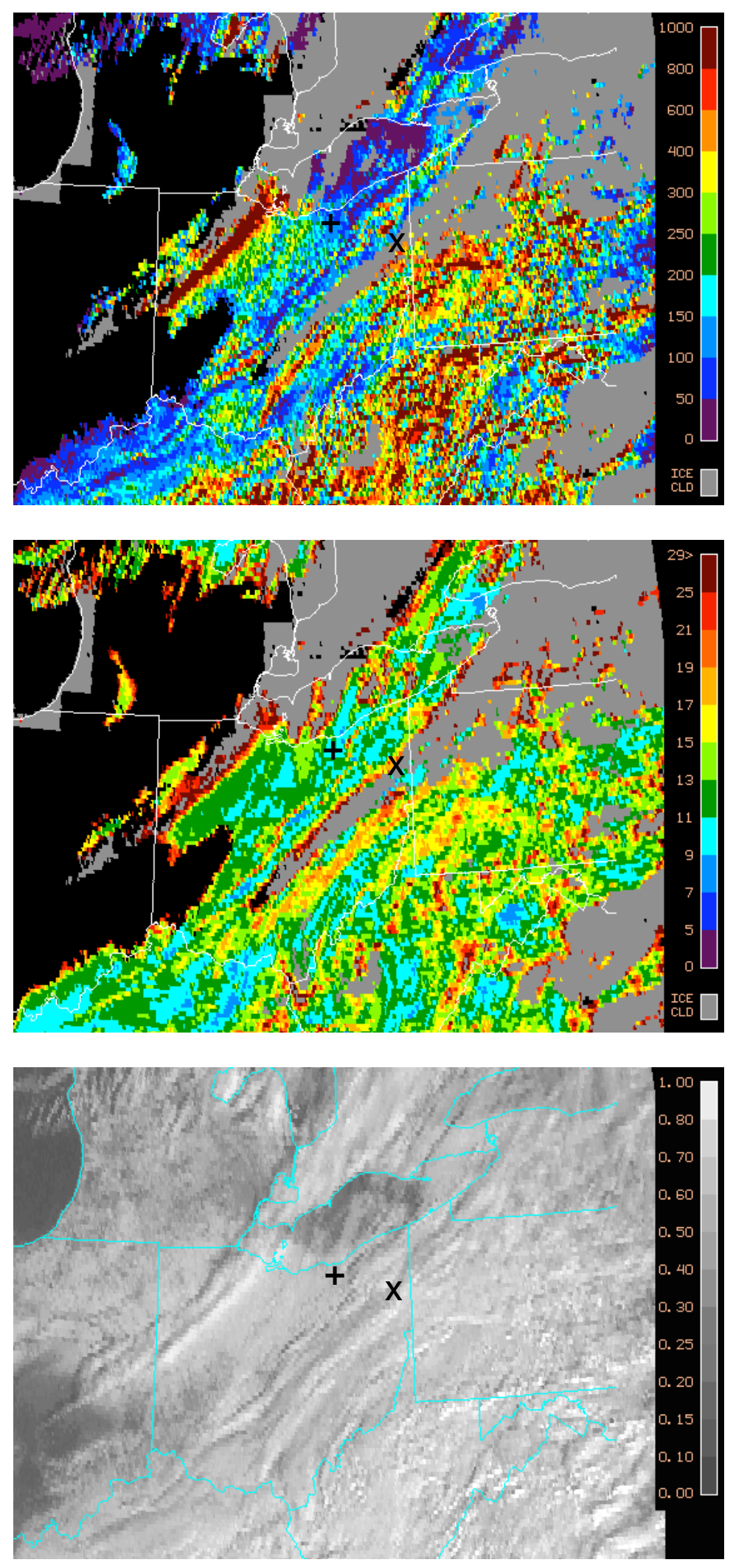

Fig. 10 - Same as Fig. 8, but for 1515 on 3 February 2005. 

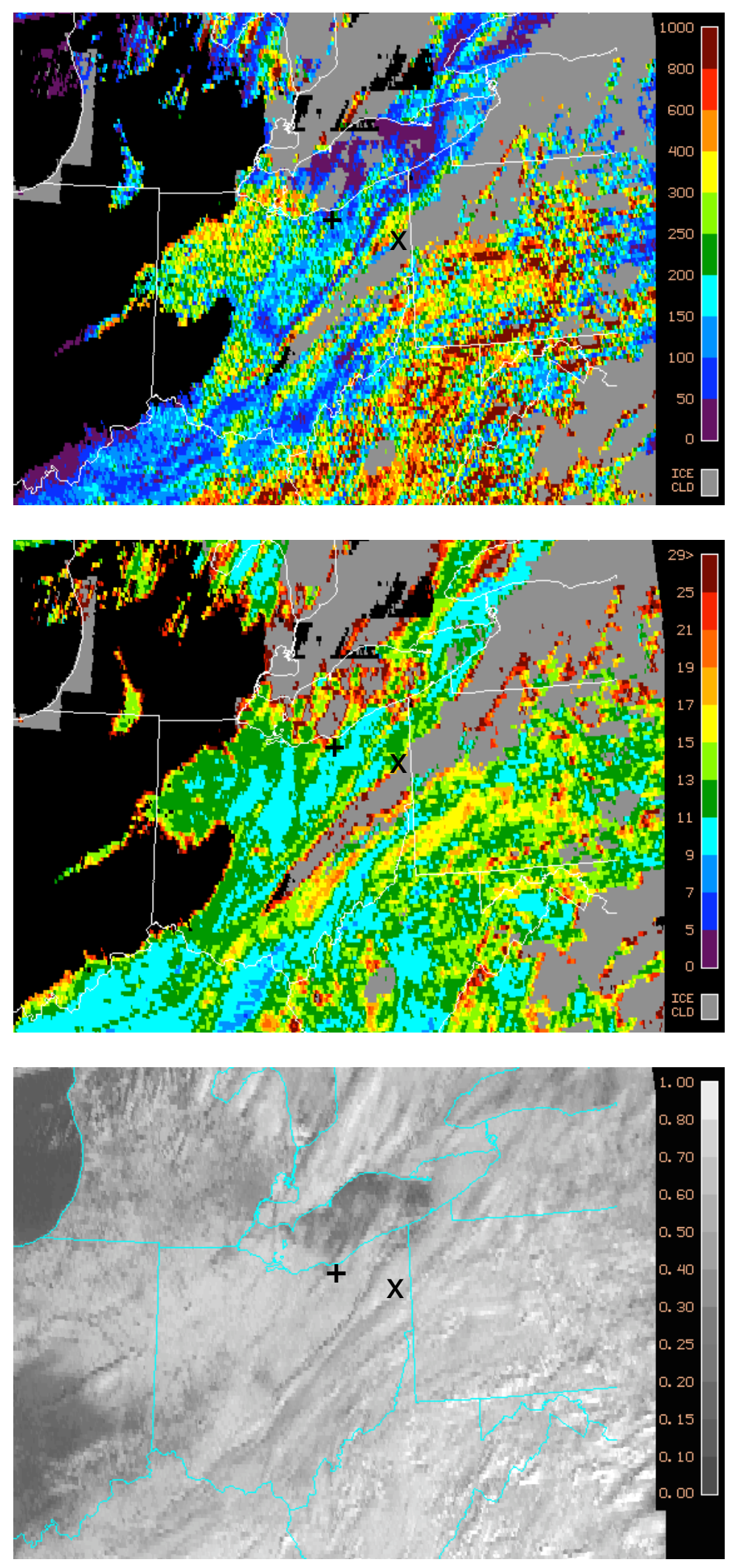

Fig. 11 - Same as Fig. 8, but for 1545 on 3 February 2005. 